\title{
EI cine como herramienta docente en psicología
}

\section{The Cinema as a Teaching Tool in Psychology}

\author{
Manuel Arboccó de los Heros (D) ORCID: https://orcid.org/0000-0002-8481-310X \\ Universidad Inca Garcilaso de la Vega, Lima, Perú. \\ Universidad Nacional Mayor de San Marcos, Lima, Perú.
}

Psicólogo y Psicoterapeuta. Magister en Psicología por la UNMSM. Docente en la Universidad Femenina del Sagrado Corazón y en la Universidad Inca Garcilaso de la Vega. Articulista del Diario El Peruano

Recibido 11-01-18 Revisado 24-01-18 Aprobado 22-02-18 En línea 26-02-18

*Correspondencia

Email: manoloarbocco@gmail.com
Citar como:

Arboccó de los Heros, M. (2018). El cine como herramienta docente en psicología. Propósitos y Representaciones, 6(1), 543-565. doi: http:// dx.doi.org/10.20511/pyr2018.v6n1.205

(C) Universidad San Ignacio de Loyola, Vicerrectorado de Investigación, 2018

(cc) BY-NC-ND Este artículo se distribuye bajo licencia CC BY-NC-ND 4.0 Internacional (http://creativecommons.org/licenses/by-nc-nd/4.0/). 


\section{El cine y su papel educativo}

En la labor docente organizamos de tanto en cuanto, ciclos de cine-fórum; un pretexto para prolongar las clases y propiciar el debate psicológico-social, para agudizar la observación, fomentar la escucha atenta, la capacidad de análisis, de paso repasar las teorías vistas en clase y, posteriormente, el sano hábito de la conversación. Un darnos tiempo para ver una buena película y reflexionar al respecto, nada tan humano como la reflexión, además de sentir, sea alegría, cólera, vergüenza, temor, todas aquellas emociones que una película (como una buena novela, un cuento, una canción o una fotografía) nos puede generar.

Hoy el cine es cada vez más sofisticado en el trabajo de los personajes y con razón es considerado uno de los grandes artes de la humanidad. Pero ¿qué ha retratado el cine si no ha sido el quehacer humano individual y colectivo? La conducta, los prejuicios, las dinámicas intra e interpersonales, "nuestros ángeles y nuestros demonios", en una palabra, la psique humana. Consideramos que a través de las películas encontramos un pretexto para prolongar la docencia y practicar la observación, el análisis, el diagnóstico y el pronóstico psíquico y social. Mirar, estar atento, escuchar, al menos dos horas y todo esto en silencio (en este mundo de ruido y estrés) y sentado, quieto, relajado (en este mundo donde queda poco espacio para la calma) es un gran ejercicio intelectual, emocional y físico.

Si bien la lista es enorme, algunas de estas películas que nos han servido para lo anterior han sido: Amadeus, La sociedad de los poetas muertos, El príncipe de las mareas, La boca del lobo, La naranja mecánica, Doce años de esclavitud, El hijo de la novia, Antes de partir, La piel que habito, Cisne negro, Los niños del coro, Kill Bill, El laberinto de Fauno, Match Point, El resplandor, Amores perros, El Rey León, La lista de Schindler, Yo soy Sam, El secreto de sus ojos, Taxi driver, Mar adentro, Belleza americana, Ciudad de Dios, Betty Blue, Hombres de honor, Los puentes de Madison, Hannahy sus hermanas, Filomena, El silencio de los inocentes, Up, La vida es bella, 
Las confesiones del Sr. Schmidt, Asesinos por naturaleza, La profesora de piano, El discurso del Rey, Tiempos modernos; entre otras grandes historias.

A continuación presentaremos algunos breves comentarios a una pequeña lista de muy buenas películas, todas ellas recomendables.

\section{Antes de partir}

“Antes de partir" es el título de una película estadounidense del 2007, dirigida por Rob Reiner y protagonizada en los papeles principales por Jack Nicholson y Morgan Freeman, ambos actores ganadores del Premio Óscar. Es la historia de dos hombres mayores, muy distintos, que se conocen en un hospital y luego de ser diagnosticados con cáncer avanzado y ser desahuciados por los médicos, deciden pasar un tiempo juntos, vivir una gran aventura y terminar algunos asuntos pendientes en sus vidas.

Observamos una rápida diferencia entre ellos durante su estadía en el hospital. Carter recibe visitas familiares mientras que Edward no. Y es que el apoyo familiar durante enfermedades como el cáncer es importante para la fase de rehabilitación.

Sabemos el impacto del componente mental en los estados de salud y enfermedad. La película también refleja el tema del estrés de los pacientes en situaciones de hospitalización y es que estar en un hospital no es una experiencia agradable. Es necesario el trabajo interdisciplinario -médicos, enfermeras, psicólogos, asistentes sociales- para conseguir que los pacientes puedan pasar una estadía en los centros de salud dentro de lo mejor posible, para eso es crucial el trato que se les da. Esto es una mirada al humano y no solo al enfermo de algo. Vemos en la película cómo Carter y luego Edward no están del todo cómodos y conformes con la atención que ahí se les da, y el estado de ánimo debe ser visto por todos como una herramienta necesaria para el bienestar integral de los pacientes. 
Es imposible pasar estos momentos de enfermedad, dolor, incertidumbre, muerte, sin atravesar por las grandes preguntas de la vida. En algún momento dialogan sobre el futuro, la muerte, el sentido, Dios y la fe.

La película nos recuerda que los antiguos egipcios tenían una peculiar creencia sobre la muerte. Al morir, en la entrada del paraíso, los dioses le hacían al alma del fallecido dos preguntas para, dependiendo de sus respuestas, ver si ésta podía entrar: 1 ¿has encontrado la dicha en tu vida?, 2 itu vida le ha brindado dicha a la vida de otros? Preguntas importantes que nos hablan del compromiso ante uno mismo, finalmente la tarea por todos (o muchos) buscada es alcanzar la felicidad junto con el contribuir con nuestra existencia al bienestar de los demás. Aquello que conocemos como la capacidad de trascendencia, algo exclusivamente humana. Carter lo dice muy bien: "Tú no eres como todos, pero todos somos parte de todos". Al final vemos como en estos tres meses que duró la relación entre estas dos personas, ambos consiguieron cierta dicha en sus vidas y contribuyeron a la del otro. Edward con su dinero, su seguridad, su actitud arriesgada y confianza, y Carter con su sabiduría, su amabilidad y su bondad.

\section{El experimento}

La película EL EXPERIMENTO (EEUU, 2010) del director Paul Scheuring trata sobre un experimento psicológico que consistió en observar el comportamiento de un grupo de voluntarios previamente entrevistados y evaluados, que pasarían dos semanas conviviendo en una prisión ficticia con la singularidad de estar divididos en dos grupos: un grupo serán los prisioneros y el resto los policías.

No es el sentido de este escrito resumir la película sino analizar algunos detalles que la misma nos muestra. Por ejemplo, el efecto que tienen en una persona el estar encerrado, el perder ciertos derechos elementales, el dejar de ser tratado por su nombre y más bien pasar a convertirse en un número. Este detalle puede iniciar una opresión que podría desencadenar, junto con 
otros elementos postrados en la película, un efecto lento de severo estrés y despersonalización.

El experimento intenta investigar como la asignación de roles (prisionero, policía) puede modificar o potenciar ciertas tendencias en los participantes. Potenciar conductas sádicas, sumisión, obediencia ciega, depresión entre otros cuadros psicopatológicos. Se muestra la sensación de poder experimentada con el transcurrir de las horas en los guardianes y nos preguntamos si no será éste un anhelo de la humanidad también. Una escena muestra al autoproclamado jefe de los guardias (representado por el actor Forest Whitaker) teniendo una erección luego de haber vivido el poder de controlar y dirigir los destinos ajenos, hay pues una erotización del poder. Este mismo manda cortar el cabello (castración) con una cuota de humillación sexual (orinarlo) al líder de los prisioneros rebeldes (encarnado por el actor Adrien Brody).

Es curioso ver como los "prisioneros" terminan aceptando el rol asignado. ¿Nos comportamos como creemos que debemos hacerlo? Salvo en el líder, no hay mayor muestra de respuesta, de ataque, frente a las injusticias vividas en esta prisión ficticia. Los prisioneros aceptan los abusos cometidos y permiten los excesos policiales. No pensamos que esto solamente se deba al dinero que hay en juego tras terminar el experimento. Teorías en psicología social han estudiado el concepto de atribuciones individuales y colectivas (asignación de roles). Sin embargo, la película también puede ser vista como el territorio de los límites a los cuáles podemos llegar por dinero y poder. Esto nos habla ya de una escala de valores, donde el dinero y el poder ocuparían un lugar principal por encima de otros valores como los sociales, los morales, los espirituales y hasta legales. Curiosamente la película está dada en los EEUU, país muy conocido por la supravaloración del poder adquisitivo y del materialismo económico que ha hecho de su importancia una bandera nacional.

Síntomas y signos en los prisioneros: Bajo fuertes dosis de presión aparece labilidad emocional, tendencia al llanto, resignación ante los 
hechos, aislamiento, confusión, sensación de impotencia y desamparo, identificación con el agresor hasta indiferencia total. También la situación de aislamiento (colocar a un prisionero en una jaula pequeña) genera confusión y alucinaciones. Es una forma de doblegar el temperamento. Se observa pérdida del cuidado personal y síntomas propios de cuadros neuróticos: dificultades para dormir, anhedonia, llanto esporádico, apatía.

En los guardianes: Se desencadena patología, quizá una patología ya latente. El momento es propicio para asumir "una nueva personalidad" mucho más autoritaria, sádica y violenta. Recuerden la escena del jefe de los guardias cortándose el cabello, puede ser un símbolo de dejar atrás un pasado y asumir otra personalidad (otra máscara). La violencia vivida en este experimento termina al salir de la cárcel, con aquella escena que nos muestra un grupo de hombres confundidos, llenos de miedo, quizá de vergüenza ante la posibilidad de haberse comportado cuál insectos o animales (como los mostrados en la primera escena de la película). Nos parece que las preguntas que se pasean por sus mentes serían ¿qué pasó acá?, ¿qué nos pasó a todos?

Una de las últimas escenas ocurre en el bus de regreso a la ciudad-luego del experimento- cuando uno de los "prisioneros" le pregunta al protagonista ¿estamos en el nivel más evolucionado de los monos? La respuesta parece ser que aún no. Al menos no cuando de situaciones- límite se trata.

Esta película está basada en el experimento de la cárcel realizada por el psicólogo social Phillip Zimbardo en la Universidad de Stanford allá en los 70, qué si bien no terminó en muerte, se tuvo que suspender varios días antes de lo pensado por encontrar manifestaciones psicopatológicas en los integrantes del experimento. Los participantes eran predominantemente blancos, jóvenes y de clase media. Todos eran estudiantes universitarios. Zimbardo y sus colaboradores los estimaron saludables y estables psicológicamente. Sugerimos revisar el experimento original. 


\section{EI hombre duplicado}

"El hombre duplicado", es una película del director Dennis Villeneuve, que trata sobre Adam, un reservado y rutinario profesor de Historia que ve alterada su monótona vida al descubrir que existe un tipo físicamente igual a él llamado Antony, un actor sin mayor éxito. La curiosidad despierta y decide ir tras él pero el encuentro le deparará mucha ansiedad, intercambiando finalmente papeles y vidas con su doble, quien lo amenaza para hacerlo.

Hay varios enfoques de análisis para esta película, desde el psiquiátrico (se trata de un sujeto con trastorno disociativo de la personalidad, antes conocido como trastorno de personalidad múltiple), el psicológico (nos habla del YO y de la identidad, además de un difícil vínculo con la madre) hasta el filosófico (aborda la individualidad en una sociedad que homogeniza y aliena).

Queremos plantear un par de preguntas que la película (la cual se basa en una obra homónima de José Saramago) nos sugiere: ¿qué pasaría si usted amable lector de pronto se encontrara con su "doble"?, descartando la posibilidad de que sea su hermano(a) gemelo(a). ¿Qué pensaría y qué sentiría? ¿Puede existir una persona idéntica a mí (a usted)? ¿Y en lo mental? ¿Qué nos define como una persona única e irrepetible? Si yo ya no soy único, original, diferente a todos, entonces ¿qué paso a ser?, pero de pronto este aspecto que nos diferencia no es lo físico, ni lo material, ni lo económico o el estilo de vida, sino lo psicológico y en especial lo espiritual, entendiendo por esta palabra lo específicamente humano, lo propio y exclusivo de los seres humanos (la autoconsciencia reflexiva, la libertad, la capacidad de valorar y de decidir).

En esta época donde ya se habla de clones humanos cabe la atingencia de recordar que clonar una psique, una mente con todas sus posibilidades, es aún ciencia ficción puesto que tendríamos que brindarle a ese "clon" las mismas experiencias, educación, padres, anécdotas, amistades, accidentes, vivencias, infortunios, de las que todos estamos hechos, y eso, es imposible. 
La investigación en Psicología de la Personalidad y en el campo de la genética conductual demuestran inclusive que los hermanos gemelos se parecen muchísimo pero aún ellos no son copias idénticas. Por suerte. Aun así, la historia narrada puede generarnos algo de intranquilidad.

\section{El príncipe de las mareas}

"El príncipe de las mareas" es una película dirigida por Barbra Streisand, quien también actúa en ella junto al actor Nick Nolte y Melinda Dillon y rodada en el año 1991. Trata la historia de una escritora, Savana Wingo, quien padece serios problemas psicológicos y tras volver a intentar suicidarse es internada en un hospital. Su psicoterapeuta, Susan Lowenstein, decide pedir apoyo a la familia conociendo así a Tom, hermano de Savana. Tom es un hombre de campo, amante del fútbol y de vida sencilla quien no entiende mucho de Psicología pero en el momento que conoce a la psicoterapeuta una serie de recuerdos y sentimientos empiezan a aparecer de su propio pasado, un pasado que está ligado al de su hermana y al origen de su psicopatología. Tom, no lo sabe, pero al ayudarla iniciará un propio encuentro consigo mismo y sus demonios.

Tom y Savana provienen de una familia disfuncional y con ese tipo de padres que crean hijos propensos a la insania mental. Se observan escenas donde claramente se aprecia cómo van programando negativamente a los hijos.

¿Puede una persona elegir no recordar? El clásico mecanismo de la represión freudiana buscaba explicar como un evento perturbador podía generar un bloqueo en la memoria del paciente, al menos una amnesia parcial que buscaría colocar esos recuerdos en esa clandestina oscuridad de la mente inconsciente. Hasta que algún evento posterior reactive el pasado perturbador. Y para Tom ese evento comienza con el nuevo intento de suicidio de su hermana. 
Tom parece un hombre insatisfecho, que intenta cumplir como padre pero le va mal en su matrimonio. Tras la noticia del intento de suicidio de su hermana, debe viajar de Carolina del Sur a Nueva York, ahora él será la memoria de Savana, situación curiosa ya que él también quiere olvidar.

La filosofía de Tom (aprendida de su madre) consiste en que cuando las cosas se ponen feas "o las evitamos o nos reímos", pero la terapeuta Susan le pregunta ¿y cuándo lloran? Así lo enfrenta a una situación natural y necesaria en el ser humano. Sabemos que el impedirse el llanto y el bloqueo sistemático del dolor humano es peligroso para la mente y el cuerpo. Por ejemplo vemos como el pasado (que nunca ha pasado del todo) interrumpe a Tom en varios momentos de la película a través de escenas que llegan a su mente. Muchos de los supuestos problemas del pasado, no han "pasado" sino que siguen vivitos y coleando y torturando. Están en el aquí y el ahora y se resisten a ser dejados de lado. Como dice el psicoterapeuta Frederick Perls "ya sea que estemos recordando o anticipando, lo estamos haciendo ahora. El pasado ya no es, el futuro aún no es" y continua “...el pasado es el pasado. Y, sin embargo, en el ahora, en nuestro ser actual, acarreamos mucho del pasado. Pero lo acarreamos únicamente en tanto que tenemos situaciones inconclusas".

Es interesante que su hermana se haya vuelto poetisa. ¿Por qué poetisa? El arte suele ser una forma de canalizar sentimientos y pensamientos poco claros, difusos, inconscientes, extraños para nosotros mismos. Los psicoanalistas lo llaman sublimación, la capacidad de conducir una fantasía, una pena, un deseo doloroso o peligroso hacia caminos reconocidos y socialmente aceptados como el arte, el trabajo, la ayuda social. Vemos como Tom es entrenador de fútbol y su hermana es poetisa.

Cosa curiosa también es que Savana empleara en algún momento una identidad distinta. Su segunda identidad es una forma de relegar a la primera, inclusive de negarla, negar la de la vida real, la de Callamwoide, la de la horrible experiencia infantil. Además elige como identidad la de una mucha judía refugiada de la persecución nazi. Así se siente Savana, perseguida, 
atormentada, sin escape. Perseguida desde la infancia por sus sentimientos, emociones e ideas. En psicoterapia sabemos que todo aquello que no suele ser entendido, aceptado y superado tiene a repetirse, a permanecer.

La película termina con Tom diciendo estas palabras: "en las familias no hay crímenes imperdonables". Aprendió a aceptar sus padres, aprendió a perdonarlos y con ello a perdonarse y aceptarse. Se liberó en parte de ese pasado esclavizador, donde sus padres eligieron llevar un mal tipo de matrimonio e influyeron mucho en su vida pero no pueden quitarle ahora las ganas de vivir, la libertad de sus elecciones y la responsabilidad de sus decisiones.

Esta película fue candidata a los premios Oscar de 1991. Recomendamos conseguirla y apreciarla. Creemos que una película, como un libro, una canción o una obra de teatro bien puede dejarnos una lección así como someterse al análisis psicológico y social de sus personajes, contenidos, tramas, y es un ejercicio valioso.

\section{You talking to me? (1)}

Se han vuelto a proyectar un grupo de películas clásicas, entre ellas una del afamado director Martin Scorsese y portagonizada por otra leyenda como es Robert De Niro. Hablamos de la película Taxi driver, el taxista (1976). La película trata la historia de Travis Bickle, un ex combatiente de Vietnam, -ahora en la ciudad de Nueva York- perturbado por su pasado y presa de intensos insomnios, jaquecas y otros síntomas, el mismo que decide trabajar por las noches como taxista conociendo así los peores lugares de la ciudad durante los años 70's. Su perturbación va en aumento y elige finalmente liberar el mismo las calles de tanta corrupción y delincuencia de las cuáles está cansado.

¿Qué comunica (el cuerpo de) Travis con esos síntomas?, ¿qué teme que ocurra al dejar la vigilia?, ¿qué miedos o terrores nocturnos le impiden cerrar un ojo? Los psicólogos han comprobado la idea que cualquier síntoma 
aparece por alguna razón, inclusive muchas veces es útil su manifestación, cumple un propósito, aunque neurótico. Además la alteración en la secuencia u orden de los ritmos del sueño y la vigilia tiene un efecto negativo a corto y largo plazo, como fatiga y desorientación, aumento de la irritabilidad, entre otros efectos.

Travis es un ex marino de la Guerra de Vietnam. Sabemos desde hace casi un siglo de las famosas neurosis de guerra. Soldados que regresaban a casa con una serie de dificultades y problemas no sólo a nivel anímico sino corporal: parálisis, contracturas, terrores nocturnos, obsesiones, que sorprendían a los médicos de entonces. Travis está en contacto con lo considerado como "lo peor" de la sociedad, el inframundo: prostitución, drogas, delincuencia, asesinatos. Reniega de su sociedad y desea limpiar la ciudad de tanta inmundicia. Nos preguntamos ¿cuánta inmundicia ve en su propio interior que es incapaz de comprender y manejar?

La película toca el tema de los soldados que regresan de combate a una ciudad para la cual no están preparados. Muchas veces sin atención psicológica ni médica regresan a una ciudad en la que no se encuentran y con la que no se identifican. Además de ser ciudades complejas y con muchos conflictos sociales. En el cine nacional podemos ver claramente esta problemática en la película Días de Santiago (Méndez, 2004), un ex combatiente del terrorismo que regresa a Lima sin una buena pensión, sin servicios de salud y educación y que presa de su pensamiento y escasa habilidad social y emocional termina inserto en una oleada de confusión y violencia. Invitamos a ver ambas películas.

(1) Un trabajo mucho más extenso del autor sobre esta película y su temática puede encontrarse en http:// revistas.uigv.edu.pe/index.php/psicologia/article/view/11/15 


\section{Referencias}

Reiner, R. (Director y productor). (2007). Antes de partir (Película). EEUU: Warner Bros. Pictures.

Scheuring, P. (Director y guionista). (2010). El experimento (Película). EEUU: Inferno Entertainment.

Scorsese, M. (Director) \& Schrader, P. (Guionista). (1976). Taxi driver (Película). EEUU: Bill/Phillips - Italo/Judeo Productions.

Streisand, B. (Directora y productora). (1991). El príncipe de las mareas (Película). EEUU: Columbia Pictures.

Villeneuve, D. (Director) y Gullón, J. (Guionista). (2013). El hombre duplicado (Película). Canadá-España: Mecanismo Films. 